\title{
Development of a 5 degree-of-freedom Towfish and its Control Strategy
}

\author{
Mohammad Aamir Khan, Aazir Khan, Matteo Zoppi, and Rezia Molfino \\ PMAR Robot Design Research Group - University of Genova, Genova, Italy \\ (Aamirkhan, khan, zoppi, molfino) @dimec.unige.it
}

Summary. This paper describes the development of a five degree of freedom towed underwater vehicle designed for condition monitoring of undersea pipelines. Its innovative design, with 6 fins actuated by 5 motors adding heave and sway capabilities to the yaw, roll and pitch movements possible in traditional designs, is explained. The parameters influencing the stability and the design in general are analyzed. A Control strategy for this design of highly coupled movements and control modes encompassing all the operational scenarios, are presented.

\section{Introduction}

In spite of significant costs due to the harsh conditions and specialized equipments required, undersea pipelines are indispensable due to geographical complexities and socio-political reasons. Because of the trawling equipments, anchors, heavy dropped objects and even ocean currents, it is necessary to protect the pipelines; and a prevalent way of doing this is by trenching and then burying the pipelines with seabed material [1]. Where the terrain is rough and rocky, levelling would also be required but pipeline would still pass through rocks along steep slopes.

Since the pipelines traverse all types of difficult trajectories and that over the period of time they get buried even deeper than the original installation due to the silt transfer or can even get uncovered, it is very challenging to track and then detect any leakage or fault along their length. Currently, gradiometers are more prevalently used to track pipelines while an ultrasonic detection system is employed for condition monitoring [2]. These gradiometers and leakage detection systems together with various auxiliary devices need to be carried by a vehicle which could be of any of these types: Remote Operated Vehicles (ROVs), Autonomous Underwater Vehicles (AUVs) and towed underwater vehicles (towfish) [3].

A towed undersea vehicle was selected to be developed for the gradiometer and leakage detection system, based on the following reasons. Firstly, it is 
much cheaper than both ROVs and AUVs because of the less complex control system and absence of the independent propulsion system. Secondly, although ROVs allow larger data transfer with mission boat due to "wired" connection with it, serving for power supply and tele-robotic control, they are best used for speeds of $1 \mathrm{~m} / \mathrm{sec}$ or less [4]. This speed falls at the lower end of the operating range in which the gradiometer is required to operate. Thirdly, although AUVs have come a long way over the years, they still have a low data transfer rate [5].

To find undersea pipeline or cable buried in the ocean floor, previously, tone generators were used. This method traditionally can only detect cable and pipeline buried at shallow ocean floor depths [6]. Magnetometer can over come this shortcoming in case of ferrous or magnetized pipelines. Conventional total-field marine magnetometers are not suitable either because they are prone to masking by background magnetic signals [7].

A gradiometer is a specialized type of magnetometer that measures a gradient of the first spatial derivative of the total magnetic field. They usually consist of two sensors (simultaneously measuring the total field strength) separated by a fixed distance [3]. The linear estimate of the gradient of the ambient field is obtained by dividing the difference in measured intensity by the distance between the sensors (baseline distance). The orientation of the gradiometer will determine which component of the three-dimensional field is measured (usually the $\mathrm{x}, \mathrm{y}$ or vertical component) [8]. Because of the ability to detect at greater depths and insensitivity to background magnetic signals they are frequently used to track pipelines.

For the detection of the leakage itself, various techniques are used in marine applications: high resolution color imaging sonars, side scan sonar, hydrophone, cathodic protection survey and ultrasonic testing [2]. According to the requirement of the end user, ultrasonic detection system was selected.

This paper describes the development of a towed underwater vehicle for tracking undersea pipeline and monitoring their state.

\section{The Operational Requirements}

The requirement was to develop an underwater vehicle with the capability to operate at a maximum depth of $300 \mathrm{~m}$, and to automatically track and monitor the condition of submerged oil pipelines. The required forward speed range is from $1.03 \mathrm{~m} / \mathrm{s}$ to $2.06 \mathrm{~m} / \mathrm{s}$ ( 2 to 4 knots) and the vehicle is towed from a ship by an umbilical. It should have the capability to track pipelines of diameter greater than $0.6 \mathrm{~m}$. The mobility requirement is that the vehicle should be able to move $16 \mathrm{~m}$ vertically and $140 \mathrm{~m}$ horizontally. This vertical figure gives enough freedom to avoid any obstacle and to follow any abrupt change. The horizontal mobility figure is based on the expected discrepancy in pipeline maps used to steer the GPS equipped towing boat roughly above the pipeline location. The vehicle should also have the translational degree of 
freedom in vertical and transverse directions together with all three rotational dofs (5dofs in total).

The stringent requirement of 5 degrees of freedom mobility was set on the bases of the several considerations. For the proper functioning of the gradiometer setup, the vehicle should move parallel to the pipeline at constant vertical and horizontal distance. The distance of the towfish from the pipes must not be less than $1.5 \mathrm{~m}$, a limit set by the condition monitoring system. The upper limit depends on the diameter of the pipe and is in the range of $5-8 \mathrm{~m}$. Underwater currents and energetic state of the sea has significant effect on the vehicle dynamics [9] and generate substantial hydrodynamic forces. As explained later, the umbilical also transmits strong disturbances to the towed vehicle $[10,11,12]$ through the ship. Due to the versatile topography of the seabed, pipelines can traverse through rocky areas with sudden unpredictable rocky obstacles for the towfish. Submerged pumping stations, concrete anchorage blocks and other infrastructure forms another obstacle. Then relatively higher forward velocity constitutes another set of constraints calling for swifter manoeuvring. Also outlined in $[13,14]$ sufficient maneuvering authority to independently control heave, and sway in addition to the roll, yaw and pitch is a desirable feature for surveillance and inspection vehicles. So, it was considered more appropriate that the vehicle has 5 degrees of freedom.

\section{State of Art}

Generally underwater towed vehicles are capable of only three rotational movements $[4,5,10,15]$. As, they approach any given point through rotational dofs., this deteriorates the quality of tracking when terrain is rocky and also when external disturbances are high. A more capable 4dof (3dof rotational and 1dof translational) design is discussed in [16]. It has 4 tail planes and 1 hydrodynamic depressor fin for depth control. Our design based on 5dof, allows the vehicle to quickly navigate laterally and vertically when required.

\section{The Vehicle's Concept and Layout}

This requirement of 5 degree of freedom makes the basic design of the vehicle substantially different from the existing vehicles and it is achieved by 6 fins controlled by 5 actuators. Labelled in Fig. 1a, fins 3 and 4 are coupled together and actuated by a single servo motor. Each of the remaining fins is actuated by a separate servo motor. The fins can be actuated to have both positive and negative angle of attack and can generate force in both directions (Lift force and down force) at the centre of pressure of the fin. These 5-dofs which are realized by the movements of the fins in various combinations are Heave, Sway, Roll, Pitch and Yaw (T2, T3, R4, R5 and R6). To illustrate the origin of the movements, a heave force $\mathrm{F}$ by fin 4 is shown to be applied. Due to 
offset from centre of gravity, roll moment and pitch moment also produce due to moment arms x and y, respectively. Similarly looking into the effect of each fins force we can summarize, Fig. 2, the pair of fin movements required to generate each of the 5 dof movement alone. From these any form of combined movement can be generated.

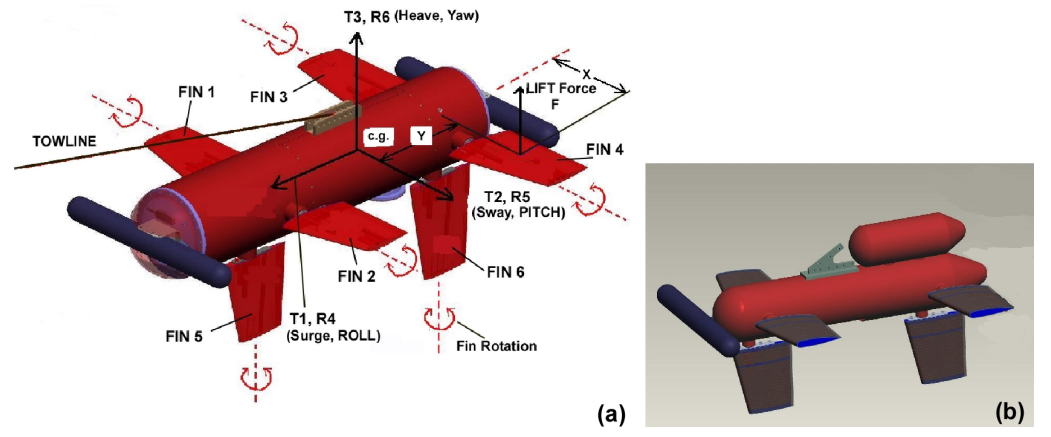

Fig. 1. (a) 3D CAD model of the towfish showing 5 dof and force on fin 4 (b) An initial concept of the towfish

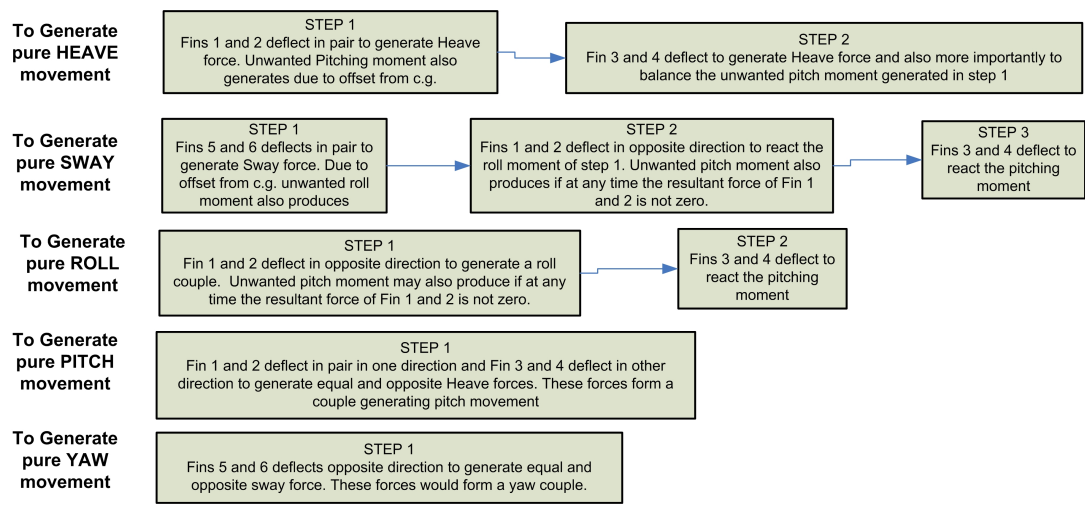

Fig. 2. Chart showing the generation of each of the 5 dof movement

The vehicle is "propelled" by a towline attached to the towing ship which pulls the vehicle forward. The towline transmits the disturbances coming from the ship, disturbances induced by the movement of the umbilical in the water and shedding vortices causing it to strum [17, 11]. On the bases of a fast control system and fin size, all of these except for axial disturbances can be compensated.

Vertical fins on the top of the vehicle could not be adopted because of hindrance to the towline, hence fins 1 and 2 remain to react the unbalance roll moment due to unsymmetrical vertical fins. An earlier concept design of shorter length with over-the-top control compartment is shown in Fig. 1b. 
The concept was dropped later due to the use of smaller control unit than the one perceived earlier, extra cost and hydrodynamically unbalanced shape.

\section{Main Modules of the system}

The vehicle is divided in three cascaded compartments joined using O-rings. The intermediate compartment is open and flooded with water. It has backbone structure, Fig. 3a, with reinforcement pipes and housing of the depth sonar mounted to it through a vertical pipe.

Both front and rear compartments are fixed to intermediate compartment through screws and normal access to the both is provided through front and rear covers. The cabling passes from front to rear compartment through the "backbone" pipe. Fig. 3b shows an exploded view of the vehicle. As the drive shafts attached to the fins is rotating, special type of lip sealing with dust wipers in series, are used.

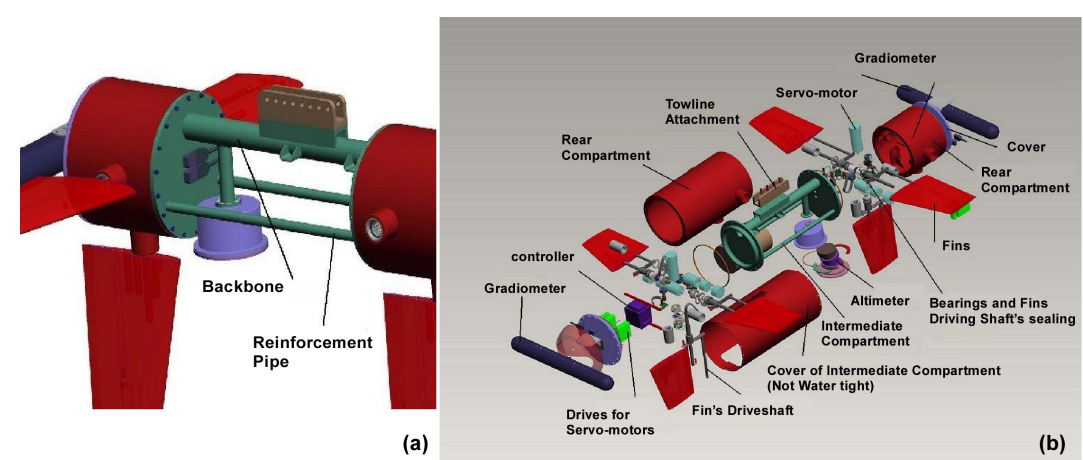

Fig. 3. (a) Intermediate compartment (b) Exploded 3D CAD view of the towfish

The 5 servo motors with reduction gears and optical encoders are identical and capable of providing peak torque of $25 \mathrm{Nm}$. As mentioned by [18], for a well performing control system most of the fin deflections are within 8 degrees. Because of the higher manoeuvrability standards the fins deflection for our vehicle was calculated to be 15 degrees. So, computing [5] on the bases of response time, the rated speed of the selected motor (12060rpm) is much higher than the required 5000rpm.

To couple the motors to driveshaft fibreglass reinforced Neoprene timing belts with customized belt tensioning mechanism are used. A sonic altimeter monitors the distance of towfish from seabed in real time and a depth pressure transducer measures the depth of the vehicle under sea surface. Two gradiometers mounted in the transverse position both at the front and rear end of the towfish, are used to control yaw and let the ends accurately track the pipeline. Roll and pitch sensors are also used. 


\section{Mobility of the Towfish}

Within water, the depth of the towline pulling the towfish is dependent on the length of the line, the type of material used and the weight of the towfish in water. With $21 \mathrm{~kg}$ as the weight of the towfish in water, obtained from buoyancy calculations, we get the Fig. 4a for 7 different cases calculated through computer coding as tabulated in the Fig. $4 \mathrm{~b}$.

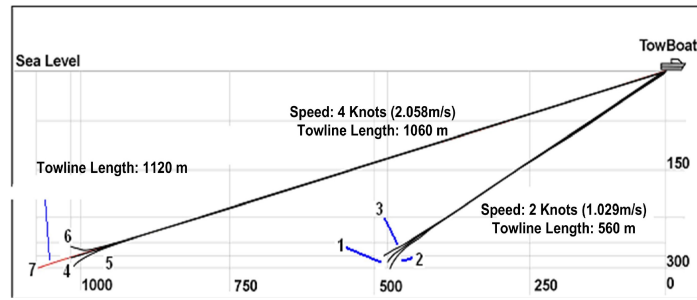

(a)

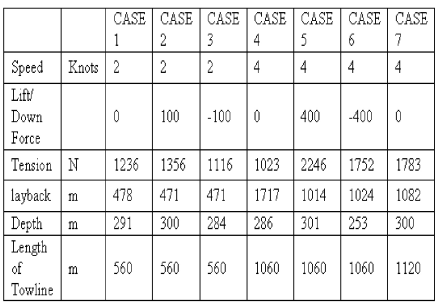

(b)

Fig. 4. (a) Illustration of Towline for different cases detailed in (b)

It can be seen that at 2 and 4 knots, the total vertical movement of the towfish is $16 \mathrm{~m}$ and $50 \mathrm{~m}$, respectively and is generated by front wing with the help of rear wing to keep towfish horizontal. In the similar way, the lateral movement permitted by the tension in towline is $140 \mathrm{~m}$ and $500 \mathrm{~m}$ for the 2 knots and 4 knots speed respectively. These minimum permitted movements of $16 \mathrm{~m}$ vertically and $140 \mathrm{~m}$ transversely satisfy the requirements laid earlier.

These movements can be varied more at higher speeds. For example, if towfish is required to rise immediately increasing the speed from 2 knots to 6 knots, at the same towline length of $560 \mathrm{~m}$, will allow the towfish to rise by $73 \mathrm{~m}$. Of course, increasing the angle of attack of the fins allows even more and faster movement.

\subsection{Fins Properties}

A NACA 0012-63 profile is used for both front and rear wings. The maximum lift at front wing predicted by the polar diagram is $71 \mathrm{~N}$ at 2 knots and 286 $\mathrm{N}$ at 4 knots which counteracting the vertical and transverse component of towline force, satisfy the mobility requirements. Because of the downwash from the front wing, the behaviour of the rear wing (used for elevation as well as lift/down force) is more complex. This phenomenon has been accounted for within the stability analysis.

\subsection{Disturbances through Towline}

The disturbances generated by the movement of the umbilical in the water depend on the umbilical used, on the mass and drag of the depressor, if used, 
and on the mass and drag of the towfish. A large part of the strumming can be removed with the use of fairing.

As far as ship disturbances are concerned, disturbances on single tows are basically characterized by two modes: pendulum mode, similar to a mass swinging on a string; bowing mode, involving back and forth bowing of the umbilical. If the connection point of the umbilical is at or slightly forward from the centre of the gravity (CG), surge and heave of the ship tow point are transmitted and result in heave disturbance of the towfish, eventually with an additional pitch disturbance due to the rear fins [10]. Because in our design the tow point is slightly forward of the CG, surge and heave in the towing cause sway in the towfish, and towfish-induced kiting, cause sway and roll, [11].

Presence of the depressor helps reduce pitch disturbances but have no effect on yaw and roll disturbances [10] and on sway or surge disturbances [12]. As evident from following section, our vehicle has more robustness in pitching mode. So, it was decided not to use depressor since it could make yaw control more difficult.

\subsection{Handling Characteristics}

Based on a mathematical model of the dynamics of the system, Fig. 5 tabulates the handling characteristics of the towfish. When angle of attack is zero, at 4 knots, the natural frequency and damping ratio are within a satisfactory range with minimum oscillations when steadying the system for normal operation; where as at 2 knots, we have small over controlling oscillations that could be overcome at control systems. In both cases, it is a stable system requiring less help from the control system (unless required to control faster).

\begin{tabular}{|c|c|c|c|c|}
\hline $\begin{array}{c}\text { Angle of } \\
\text { Attack }\end{array}$ & $\begin{array}{c}\text { Vehicle speed } \\
\text { (Knots) }\end{array}$ & $\begin{array}{c}\text { Natural } \\
\text { frequency } \\
\text { (rad/s) }\end{array}$ & Damping ratio & $\begin{array}{c}\text { Time to half for } \\
\text { pitch oscillation } \\
(\mathrm{s})\end{array}$ \\
\hline 0 & 2 & 0.8361 & 0.4508 & 3.3056 \\
\hline 0 & 4 & 2.0304 & 0.4508 & 1.361 \\
\hline Max & 2 & 3.2354 & 0.1556 & 1.3764 \\
\hline Max & 4 & 0.82354 & 0.1556 & 3.3447 \\
\hline
\end{tabular}

Fig. 5. Handling characteristics at different vehicle speeds

In the case of max. angle of attack, the towfish is required to vertically climb and fall without any pitching moment, and therefore the rear wing is driven to control that moment as well as provide some extra lift (or down force). System is still very stable. The handling characteristics are much more prone to over controlling oscillations, but those can be adjusted by precision controlling by the control system. 


\section{CONTROL SYSTEM OVERVIEW}

Careful engineering of the hardware and software systems, supervising the robotic system mission, has been performed, particularly considering the equipment installed, the data exchange and the performance in different operative modes. Several aspects have been carefully investigated at the level of sensory system selection and control modules design: pipe engagement, pipe tracking, towfish deployment and recovery, pipe monitoring and inspecting.

The Fig. 6(a) shows the control and monitoring system layout. The control system comprises of a surface control unit and the monitoring unit running diagnostic applications, a surface-to-underwater interface and analogical/digital control unit; the towfish equipment, includes actuators, sensors, alarms besides the monitoring device module and various other equipment. The surface control unit reads all sensor signals from the sub-sea unit and presents the scaled values on the monitor.

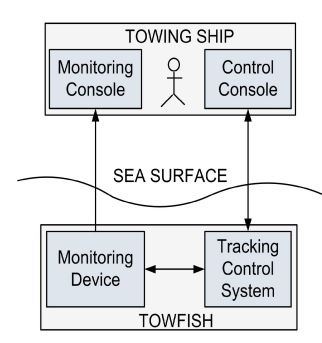

(a)

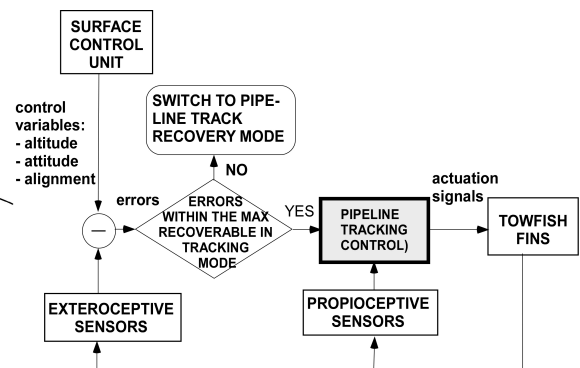

(b)

Fig. 6. Control system schemes

To enhance the system reliability and maintainability, a modular approach has been adopted in the control design. Operative missions are performed as sequence of different tasks, accomplished by pertinent control modules. Every module is designed to achieve a particular goal. A human supervisor can check, in real time, the progress of the missions. As far as possible and acceptable, standard equipment, software, and transmission protocols have been chosen.

Fig. 6(b) shows the main control loop of the system. Propioceptive sensors include the yaw, pitch and roll sensors, while altimeter, gradiometer, depth pressure transducer and pipeline monitoring system are grouped as exteroceptive sensors. They jointly measure the instantaneous state of the towfish in term of underwater depth, distance from seabed, roll, yaw and pitch angles and gradient of the magnetic flux. If the errors in position are beyond the range of normal tracking mode then track recovery mode is actuated and human intervention will be required to return the towfish on normal course through tele-control of fins and/or towline manipulation.

For illustration purpose, one towfish manoeuvring situation is described here in which movement of the towing ship suddenly shifts the towfish away 
from the pipeline causing the impairment in condition monitoring task. Data from the two gradiometers show that the vehicle needs to move in lateral direction swiftly and that yaw angle also needs to be corrected. The motion vector is determined by the 3 dimensional field of the gradiometer as shown in the Fig. 7a.

To get it back again on the normal course, a series of the fins movements would be required. Fin 5 and 6 would deflect to generate the lateral force and their differential forces would compensate of the yaw change as well. In doing so, a roll moment would be generated due to the offset of the centre of forces from towfish centreline. Fins 1 and 2 would deflect in opposite directions to react this roll moment. Any transient pitch moment or yaw moment (and movements) would be reacted or corrected by the fins pairs $(3,4)$ and $(5,6)$, respectively. The elevation can be corrected by the pairs $(1,2)$ and $(3,4)$.

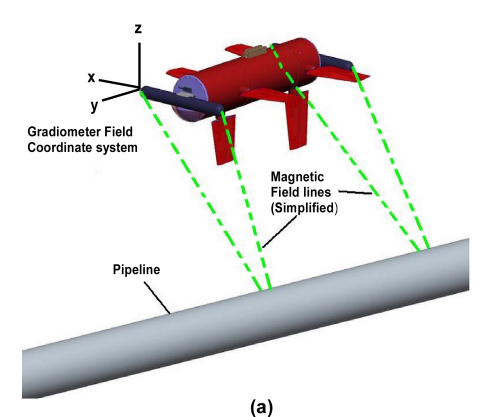

(a)

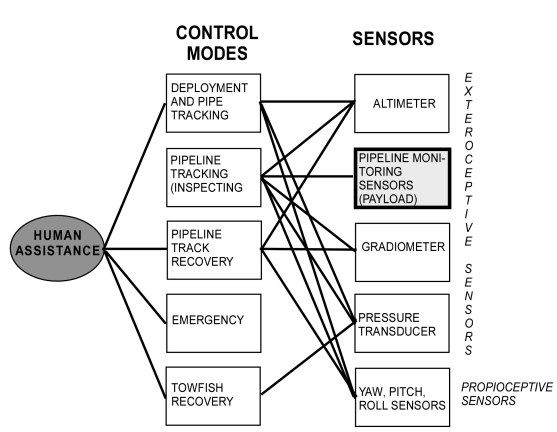

(b)

Fig. 7. (a) Illustration of how gradiometer helps to find and align with pipe (b) Control Modes

Various control modes and the sensors employed are shown in Fig. 7b. Three emergency modes are activated when sea-bed is very close, sea-surface is close and fins stall. Fins actuation to obtain maximum upwards and downwards forces are emergency measures for first and second mode. For the stall emergency mode, effective angle of attack of fins will be extracted from the yaw, roll and pitch sensors and maximum corrective measure will be taken at fins.

The amount of information displayed and the control functions available to the operator are set individually for each control mode. In emergency mode, the value of all sensors are displayed, and all controls are available for the operator. Each mode will have direct access to the equipment necessary for its limited operation. If other equipment shall be operated, the manual override is necessary. The emergency mode has access to all functions and can automatically override current tasks by shut down procedures. The alarms are arranged for a number of parameters; the shut down is enabled only for a limited number of catastrophical events. 


\section{Conclusion}

This paper presented the design of a towfish which is intended to have high mobility and maneuverability than traditional designs to track the undersea pipelines more effectively. It also highlighted general design requirements for the application and presented a model of interaction between environment and towfish. Preliminary tests has been successfully conducted (high pressure tests and tracking of a metallic wire in a $500 \mathrm{~m}$ pool).

\section{References}

1. Naxans (2006) White Paper Oil and Gas www.nexans.com/ Corporate/2007/Nexans_White_Paper_Oil_Gas_April.

2. Mastandrea JR, Miller WJ, Clare DM (1990) Rapid Leak Detection for Sea Floor Pipelines: Development of Practical New Methods. In: NDE Technical Report No. NDE-90R0081601. NDE Environmental Corporation, California

3. Pozza M, Hrvoic D, Priddis K (2003) Mapping Marine Ferrous Targets Using the SeaQuest Gradiometer System. Technical Report Marine Magnetics Corp

4. Linklater A (2005) Design and simulation of a towed underwater vehicle. MS Thesis, Virginia Polytechnic Institute and State University, Virginia

5. Schuch EM (2004) Towfish Design, Simulation and Control. MS Thesis, Virginia Polytechnic Institute and State University, Virginia

6. Innovatum (2000) Magnetization Technology Locates Undersea Pipes, Pipeline and Gas Journal, 8:227

7. MacLeod IN, Vierra S, Chavew AC (1993) Analytic signal and reduction-tothe-pole in the interpretation of total magnetic field data at low magnetic latitudes. In: Proc. of the third international congress of the Brazilian society of geophysics

8. Roest WR, Verhoef J, Pilkington M (1992) Geophysics 57:116-125

9. Ananthakrishnan P, Decron S (2000), Dynamic Stability of Small and MiniAutonomous Underwater Vehicles: Part I. Analysis and Simulation for Mid water Applications, Technical Report, Florida Atlantic University, Florida

10. Preston JM (1992) Stability of Towfish used as Sonar Platforms. In: Oceans '92 Proceedings of Mastering The Oceans Through Technology, Newport

11. Crane JW, Humphreys DE (1992) Modeling and simulation of underwater vehicles. In: SCS Summer Simulation Conference, Baltimore

12. Jiaming W, Chwang AT (2000) Ocean Engineering 27:455-472.

13. Licht S, Polidoro V, Flores M, Hover FS, Triantafyllou MS (2004) IEEE JOURNAL OF OCEANIC ENGINEERING 29(3):786-794

14. Anan CS (2001) Autonomous Underwater Robot: Vision and Control. MS Thesis, The Australian National University, Canberra

15. Fossen TI (1994) Guidance and Control of Ocean Vehicles. John Wiley and Sons, New York

16. Buckham B, Nahon M, Seto M, Zhao X, Lambert C (2003) Journal of Ocean Engineering 30:453-470

17. Chapman DA (1982) Ocean Engineering 9(3):189-220.

18. Rodriguez RR (1997) Performance Evaluation of the Control Surface Actuators for the Towed Body for Mine Countermeasures Sensor Testing. In: Technical Report CSS/TR-97/20, Naval Surface Warfare Center, Panama City 